\title{
Philippine rice wine (Tapuy) made from Ballatinao black rice and traditional starter culture (Bubod) showed high alcohol content, total phenolic content, and antioxidant activity
}

\author{
Jared Gabriel Lopez DELA ROSA ${ }^{1}$, Paul Mark Baco MEDINA ${ }^{1 *}$
}

\begin{abstract}
This study described and evaluated the acidity, alcohol content, total phenolic content, antioxidant activity, and sensory attributes of rice wine (Tapuy) made from black, red, brown and white rice during a 7-day fermentation. Acidity of Tapuy made from the different pigmented rice had similar $\mathrm{pH}$ profiles characterized by a steep decrease at day 1 from $6.38 \pm 0.4$ to $3.38 \pm 0.2$, and remained relatively unchanged until the end of fermentation. Tapuy made from black rice (Ballatinao) contained 16.07\% alcohol, second to white rice (Bongkitan) that contained $18.58 \%$ alcohol, although they were not significantly different from each other $(\mathrm{p}>0.05)$. At the end of fermentation, the total phenolic content and antioxidant activity of Tapuy made from black rice was significantly higher $(\mathrm{p}<0.05$ and $\mathrm{p}<0.01$, respectively) than Tapuy made from the other pigmented rice. Total phenolic content of Tapuy made from black rice was at $9.73 \mathrm{mg} \mathrm{GAE} / \mathrm{mL}$ and antioxidant activity leveled-off at 70.63\% DPPH radical scavenging activity; whereas Tapuy made from the other pigmented rice were declining. Thus, Ballatinao black rice is a suitable rice variety for making Tapuy and has the potential to be a health-promoting functional food.
\end{abstract}

Keywords: antioxidant activity; Ballatinao black rice; fermentation; rice wine.

Practical Application: Use of Ballatinao black rice is a healthier alternative than glutinous white rice to make Tapuy.

\section{Introduction}

Fermentation causes many biochemical changes in food products that can alter the ratio of nutritive and anti-nutritive components resulting to altered properties of the food material, such as bioactivity and digestibility (Zhang et al., 2012). Increasing consumer awareness with diet-disease relationships have attracted scientific interest in fermentation and how it can increase the health-promoting benefits of food products (Xiang et al., 2019). Fermentation can improve the antioxidant activity of food products by increasing the release of bioactive phenolic compounds and flavonoids in plant-based products (Hur et al., 2014; Lee et al., 2008). Fermentation can also produce probioticrich food products that can have positive effects on memory enhancement by improving gut health properties (Gobbetti et al., 2010; Selhub et al., 2014). The health-promoting benefits, particularly antioxidant activity, of fermented food products can be attributed to the carbohydrate-metabolizing enzymes produced during fermentation that promotes the bioconversion of phenolic glycosides into their free form, i.e. aglycones, which have high antioxidant activity (Vattem \& Shetty, 2003).

The Philippines has many traditional fermented food products including fermented rice, fermented fish, fermented mustard leaves, fermented green mango, coconut wine, palm vinegar and many others (Sanchez, 1999). Tapuy is a traditional fermented food product popular in the Northern part of the Luzon island specifically Benguet, Ifugao, and the Mt. Provinces (Sakai \& Caldo, 1985). It is an alcoholic sweet-acidic beverage that is produced by the simultaneous saccharification and fermentation of glutinous white rice (Sanchez, 2008). Tapuy is produced using the traditional starter culture, Bubod, which are dried discs of ground glutinous rice, wild grass roots (Bidens pilosa), ginger and old Bubod (Sanchez, 1999). This local rice wine is part of the culture and tradition of the Cordillera people who consume it during festivities and traditional ceremonial occasions (Bandonill et al., 2009; Sanchez, 1999). The traditional methods of making Tapuy vary in the different Northern Luzon provinces which resulted in the various quality of Tapuy from one maker to the other and from one locality to another (Tanimura et al., 1977). All these methods of making Tapuy have been developed on a trial and error basis, passing down this Tapuy making process from one generation to another (Sanchez, 1999). Several efforts have been made in producing consistent quality for Tapuy such as development of protocols for the standardization of Tapuy production for commercial purposes headed by the Philippine Rice Research Institute (PhilRice) (Ablaza et al., 2008; Bandonill et al., 2009).

Rice (Oryza sativa L.) is the most important cereal crop produced in Asia that is consumed as a staple food by nearly half of the world's population (Huang \& Lai, 2016; Priya et al., 2019). Rice cultivars exists in different colors such as white, brown, red, purple and black (Kushwaha, 2016). White rice is the rice cultivar most consumed by humans (85\%) while the rest are the colored or pigmented rice (Ling et al., 2001). Pigmented rice, however, are nutritionally superior and have richer taste compared to common white rice (Kushwaha, 2016; Su et al., 1998). Pigmented rice contains 
anthocyanins and proanthocyanidins which have antioxidant (Rattanachitthawat et al., 2010), anti-inflammatory (Wang et al., 2007), cardioprotective and antiatherogenic activities (Ling et al., 2001). Pigmented rice was historically cultivated in Southeast Asian countries, however, China and India, including Thailand, are now the major producers of pigmented rice (Kong et al., 2008; Prasad et al., 2019). In the Philippines, Ballatinao is a glutinous black rice variety found in the northern regions of the country. It is considered as an heirloom rice by the indigenous people of the Cordillera and is served during ceremonial festivities and traditional practices (PhilRice, 2017). Compared to the local red rice and non-pigmented rice, Ballatinao black rice had the highest anthocyanin content, total phenolics, crude protein and crude fat (Romero et al., 2012). Black rice varieties generally have high anthocyanin content (Hou et al., 2013), and several countries in Asia are exploring this feature to produce rice wine with high antioxidant activities, including India, Japan, Korea, China, Thailand, and Cambodia (Chay et al., 2020; Jiang et al., 2020b; Kim et al., 2012; Moirangthem et al., 2020; Singkong, 2015; Takeshita et al., 2015). In the Philippines, Ballatinao black rice is already used in Tapuy making, but to our knowledge, no studies have been done describing the use of this black rice variety in Tapuy production. Utilization of the Ballatinao black rice in Tapuy production can help promote the local heirloom rice industry and preserve the cultural practices of the Cordillera people surrounding this heirloom rice. This study characterized the acidity, alcohol content, total phenolic content, antioxidant activity, and sensory attributes of Tapuy made from Ballatinao black rice, Kintoman red rice, Tinawon brown rice, and Bongkitan white rice during a 7-day fermentation.

\section{Materials and methods}

\subsection{Starter culture}

Traditional starter culture, or Bubod, was purchased at a local market in Baguio City, Philippines.

\subsection{Rice grains}

Two glutinous rice varieties - black rice (Ballatinao) and white rice (Bongkitan), and two non-glutinous rice varieties brown rice (Tinawon) and red rice (Kintoman), were purchased at a local market in Baguio City, Philippines (Figure 1).

\subsection{Chemicals}

DPPH (1,1-diphenyl-2-picrylhydrazyl) was purchased from Sigma-Aldrich, Inc. (St. Louis, MO, USA). Ascorbic Acid was purchased from Chemline Scientific Corporation (Quezon City, Philippines). Potassium Dichromate $\left(\mathrm{K}_{2} \mathrm{Cr}_{2} \mathrm{O}_{7}\right)$ and Sulfuric acid $\left(\mathrm{H}_{2} \mathrm{SO}_{4}\right)$ were provided by the Department of Biochemistry and Molecular Biology Laboratory, University of the Philippines Manila.

\subsection{Fermentation procedure}

Tapuy was prepared as follows: $5 \mathrm{~g}$ of uncooked rice and $10 \mathrm{~mL}$ of deionized water were placed into a $50 \mathrm{~mL}$ Erlenmeyer flask and autoclaved at $121{ }^{\circ} \mathrm{C}$ for 15 minutes. After cooling, $2 \mathrm{~g}$ of ground Bubod and $8 \mathrm{~mL}$ of deionized water were added into the Erlenmeyer flask and mixed with the cooked rice. The Erlenmeyer flasks were sealed using cork and placed in an incubator set at $25^{\circ} \mathrm{C}$. Rice wine samples were then collected every day, from day 0 until day 7 of fermentation. This was done by filtering the mash made from the rice grains collected. The collected rice wine, or Tapuy, was then analyzed.

\subsection{Determination of acidity}

The acidity of the Tapuy was determined using an Orion pH meter MDI 420A (Vernon Hills, IL, USA).

\subsection{Determination of alcohol content}

Alcohol content of the Tapuy was determined by the EthanolDichromate assay based on the method of Sumbhate et al. (2012). $0.25 \mathrm{M} \mathrm{K}_{2} \mathrm{Cr}_{2} \mathrm{O}_{7}$ and $6 \mathrm{M} \mathrm{H}_{2} \mathrm{SO}_{4}$ were prepared and $50 \mu \mathrm{L}$ each of the solution was mixed together and added to $100 \mu \mathrm{L}$ of Tapuy. The reaction was allowed to occur for five minutes and then read at $570 \mathrm{~nm}$ against a standard curve generated from different concentrations of ethanol.

\subsection{Determination of total phenolic content}

Total phenolic content of the Tapuy was determined by Folin-Ciocalteu method with modifications. $15.4 \mu \mathrm{L}$ of wine samples and gallic acid standard (at different concentrations) were mixed with $61.5 \mu \mathrm{L}$ of Folin-Ciocalteu reagent (diluted 1:10 with deionized water) and were neutralized with $123 \mu \mathrm{L}$ of $7.5 \%$ sodium carbonate. The mixtures were allowed to stand at

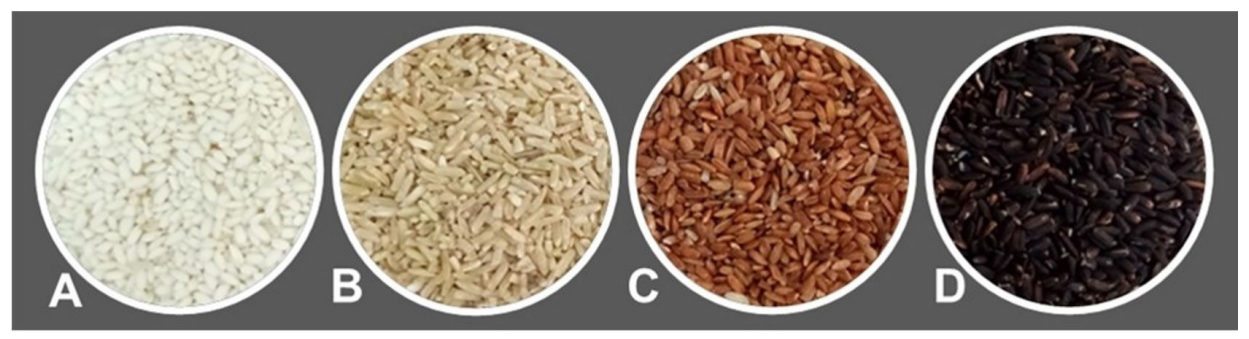

Figure 1. Pigmented rice varieties used in the study. (A) White rice (Bongkitan); (B) Brown rice (Tinawon); (C) Red rice (Kintoman); (D) Black rice (Ballatinao). These heirloom pigmented rice varieties were cultivated at high altitude areas in the Cordillera region and are sold at local markets in the Cordillera provinces. 
room temperature for 30 minutes. The absorbance was measured at $765 \mathrm{~nm}$. The results were expressed as gallic acid equivalents (mg GAE/mL).

\subsection{Determination of antioxidant activity}

Antioxidant activity of the Tapuy was determined using the 1,1-diphenyl-2-picrylhydrazyl (DPPH) radical scavenging assay based on the method of Prieto (2012). $0.2 \mathrm{mM}$ DPPH solution in $95 \%$ ethanol was prepared and $100 \mu \mathrm{L}$ of this solution was added to $100 \mu \mathrm{L}$ of Tapuy. The reaction was allowed to occur for 30 minutes in the dark and then read at $517 \mathrm{~nm}$. DPPH radical scavenging activity was obtained using the following Formula 1:

$\%$ DPPH Radical Scavenging Activity $=100 \% \times \frac{\mathrm{Abs}_{\mathrm{DPPH}+\text { Water }}-\mathrm{Abs}_{\mathrm{DPPH}+\text { Sample }}}{\mathrm{Abs}_{\mathrm{DPPH}+\text { Water }}}$

where $\mathrm{Abs}_{\mathrm{DPPH}+\text { Water }}$ is the absorbance of the control reaction and $\mathrm{Abs}_{\mathrm{DPPH}+\mathrm{Sample}}$ is the absorbance of the Tapuy sample.

\subsection{Sensory evaluation}

Sensory evaluation of the Tapuy made from different pigmented rice was based on the method of Chay et al. (2017). $15 \mathrm{~mL}$ of wine samples were dispensed in a clean shot glass coded with 3-digit random numbers and placed on serving plates. 20 panelists recruited among students, faculty and staff members of the University of the Philippines, Manila (Manila, Philippines), evaluated the sensory attributes of the Tapuy. The panelists were asked for preferences to color, clarity, aroma, sweetness, sourness, and bitterness using a score sheet with a scale of 1 to 9 , where: Color: $1=$ Extremely light color, $9=$ Extremely dark color; Clarity: 1=Extremely clear, 9=Extremely cloudy; Aroma; 1=Extremely weak, 9=Extremely strong; Sweetness: 1=Extremely not sweet, 9=Extremely sweet; Sourness: 1=Extremely not sour, 9=Extremely sour; Bitterness: 1=Extremely not bitter, 9=Extremely bitter.

\subsection{Statistical analyses}

All statistical analyses were performed using SPSS version 23 (IBM Corp., Armonk, NY, USA). All experiments were done in triplicates. Analysis of variance (ANOVA) was performed using the general linear model procedure to determine significant differences among the samples. Means were compared by using Tukey's honest significant difference (HSD) test. Significance was defined at the $5 \%$ level.

\section{Results and discussion}

\subsection{Tapuy made from different pigmented rice have similar acidity profiles}

The $\mathrm{pH}$ of Tapuy made from different pigmented rice are shown in Figure 2. The different rice wines exhibited a $\mathrm{pH}$ range of 2.94 to 3.60 during the 7-day fermentation, with a final $\mathrm{pH}$ range of 3.16 to 3.40 . These $\mathrm{pH}$ values were not significantly different from each other ( $\mathrm{p}>0.05)$, and fall within the $\mathrm{pH}$ range (3.01-3.74) of indigenously-produced commercial Tapuy from Benguet, Philippines (Hipol \& Alma-in, 2018). Similar pH values were also exhibited by rice wines made from pigmented rice from other Asian countries (Baek et al., 2013; Takeshita et al., 2015; Teramoto et al., 2011). A steep decrease in $\mathrm{pH}$ from day 0 to day 1 of fermentation was noted for all the different Tapuy (Figure 2). This steep decrease in $\mathrm{pH}$ was not unusual since it has also been observed during the fermentation of Makgeolli, a Korean traditional rice wine (Kim et al., 2013). This decrease in $\mathrm{pH}$ of the Makgeolli was associated with the production of organic acids by microorganisms (e.g. lactic acid bacteria) during the first day of fermentation (Jin et al., 2008; Lee et al., 2009). Lactic acid bacteria were also found in Tapuy which were made using the traditional starter culture (Bubod) (Sanchez, 1999), the same starter culture used in this study. The weakly acidic $\mathrm{pH}$ of Tapuy may also be attributed to the production of carbonic acids from the reaction of alcohol and $\mathrm{CO}_{2}$ with water during fermentation (Singkong, 2015). The acidity, coupled with the presence of volatile compounds, affect the flavor quality and shelf life of rice wines (Lee et al., 2009).

\subsection{Tapuy made from black and white rice had the highest alcohol content}

The alcohol content of Tapuy made from different pigmented rice are shown in Figure 3. There was an increase in the alcohol content of the different rice wines during the 7-day fermentation. The final alcohol content of the rice wines after fermentation was 9.13 to $18.58 \%$ (Figure 3 ). These values fall within the range of alcohol contents (8.19-19.83\%) of commercial Tapuy from Benguet, Philippines (Hipol \& Alma-in, 2018). Similar alcohol contents (14-18\%) were also shown in Makgeolli (Jin et al., 2008) and the traditional Guizhou black glutinous rice wine from China (Jiang et al., 2020b). The increase in alcohol content during fermentation was expected as it is brought about by the concerted action of molds and yeast in hydrolyzing rice starch into glucose and converting glucose into ethanol, respectively (Jiang et al., 2020a; Kim et al., 2013). Bubod from the Cordillera region contains molds and yeasts (e.g. Aspergillus oryzae,

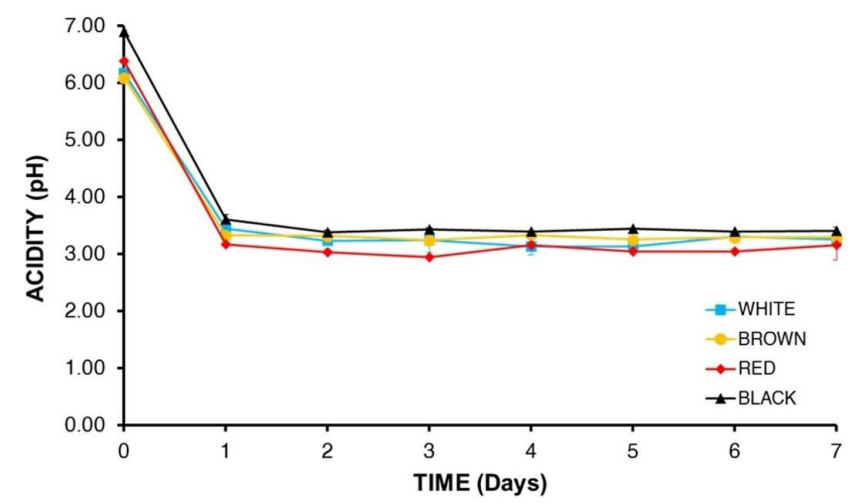

Figure 2. Acidity $(\mathrm{pH})$ of Tapuy made from different pigmented rice during the 7-day fermentation. Data points are the mean of 3 replicates. Error bars are the standard deviation for each data point. Tapuy made from different pigmented rice exhibited a $\mathrm{pH}$ range of 2.94 to 3.60 during the 7-day fermentation. The $\mathrm{pH}$ profiles of all Tapuy showed a steep decrease in $\mathrm{pH}$ from day 0 to day 1 and remained relatively unchanged throughout fermentation. The final $\mathrm{pH}$ of the different Tapuy range from 3.16 to 3.40 which were not significantly different from each other $(\mathrm{p}>0.05)$. ${ }^{*} \mathrm{p}$-value $<0.05$. 


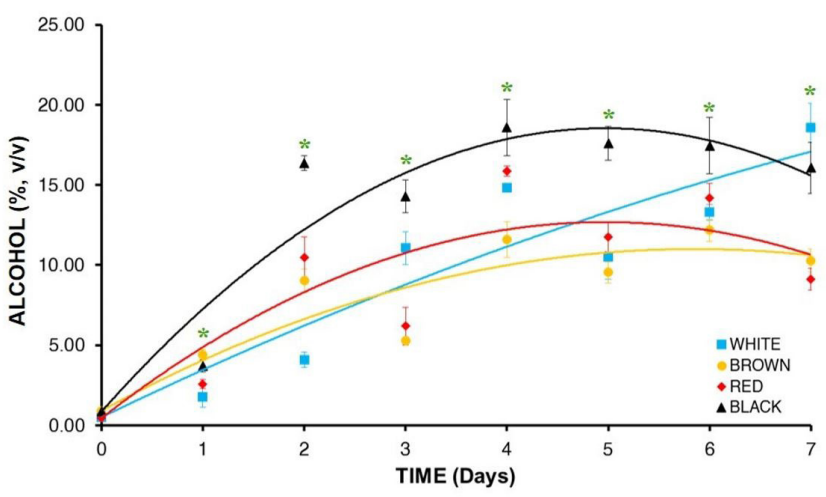

Figure 3. Alcohol content (\%) of Tapuy made from different pigmented rice during the 7-day fermentation. Data points are the mean of 3 replicates. Error bars are the standard deviation for each data point. Lines are the best-fit curve using a $2^{\text {nd }}$ order polynomial equation. There was an increase in the alcohol content of Tapuy made from different pigmented rice throughout fermentation. The final alcohol content of the different rice wines after fermentation was 9.13 to 18.58\%. Tapuy made from Ballatinao black rice and Bongkitan white rice showed significantly higher $(\mathrm{p}<0.01)$ final alcohol content $(16.07 \%$ and $18.58 \%$, respectively) than red rice and brown rice $(9.13 \%$ and $10.26 \%$, respectively). ${ }^{*}$ p-value $<0.01$.

Table 1. Total phenolic content (mg GAE/mL) of Tapuy made from different pigmented rice after the 7-day fermentation.

\begin{tabular}{cc}
\hline Rice Variety & Total Phenolics $(\mathrm{mg} \mathrm{GAE} / \mathrm{mL})$ \\
\hline White rice (Bongkitan) & $7.52^{\mathrm{a}} \pm 0.04$ \\
Brown rice (Tinawon) & $8.59^{\mathrm{b}} \pm 0.04$ \\
Red rice (Kintoman) & $9.08^{\mathrm{c}} \pm 0.03$ \\
Black rice (Ballatinao) & $9.73^{\mathrm{d}} \pm 0.14$ \\
\hline
\end{tabular}

Data values are the mean of 3 replicates \pm standard deviation. Tapuy made from different pigmented rice exhibited a total phenolic content ranging from 7.52 to $9.73 \mathrm{mg} \mathrm{GAE} /$ $\mathrm{mL}$ after the 7-day fermentation. Tapuy made from black rice showed the highest total phenolic content $(9.73 \mathrm{mg}$ GAE/mL, $\mathrm{p}<0.05)$ among the Tapuy made from different pigmented rice. Mean values with different superscripts are significantly different at $5 \%$ level, as determined by Tukey's honest significant difference (HSD) test.

Rhizopus oryzae, Saccharomyces cerevisiae, Mucor rouxii) which are responsible for the increase in alcohol content of the Tapuy during fermentation (Banwa et al., 2020; Sanchez, 1999). Tapuy made from white rice and black rice showed a final alcohol content of $18.58 \%$ and $16.07 \%$, respectively (Figure 3 ). These values are significantly higher $(\mathrm{p}<0.01)$ compared to the final alcohol content of Tapuy made from red rice and brown rice (9.13\% \& $10.26 \%$, respectively). The higher alcohol content of Tapuy made from white rice and black rice, compared to Tapuy made from red rice and brown rice, was likely due to the larger number of fermentable saccharides found in glutinous rice, which were shown to produce higher alcohol content in rice wines (Coronel et al., 1981; Lai et al., 2019; Zhao et al., 2009).

\subsection{Tapuy made from black rice had the highest total phenolic content}

Phenolic compounds are diverse plant metabolites that have many health-promoting bioactivities, e.g. antimicrobial, anti-inflammatory, anti-thrombotic, and antioxidant activity
(Shahidi \& Ambigaipalan, 2015). The total phenolic contents of Tapuy made from different pigmented rice are shown in Table 1. The different rice wines exhibited a total phenolic content ranging from 7.52 to $9.73 \mathrm{mg}$ GAE/mL after the 7 -day fermentation. These values were significantly different $(\mathrm{p}<0.05)$ from each other with Tapuy made from white, brown, red, and black rice showing an increasing total phenolic content. This finding may be attributed to the varying amounts of anthocyanins in the different pigmented rice. Romero et al. (2012) showed that Ballatinao black rice had the highest total phenolic $(9.30 \mathrm{mg}$ GAE/g) and anthocyanin $(5,674 \mathrm{mg} / \mathrm{mL})$ contents compared to red rice $(6.18 \mathrm{mg} \mathrm{GAE} / \mathrm{g} \& 60.9 \mathrm{mg} / \mathrm{mL})$ and non-pigmented or white rice $(1.03 \mathrm{mg} \mathrm{GAE} / \mathrm{g} \& 42.7 \mathrm{mg} / \mathrm{mL}$ ). The total phenolic contents of the different rice wines in this study were 10 -fold higher compared to the total phenolic content of commercial Tapuy from Benguet, Philippines (118-303 $\mu \mathrm{g}$ GAE/mL) and commercial $100 \%$ orange juice $(0.77 \mathrm{mg} \mathrm{GAE} / \mathrm{mL})$, which is considered a healthy beverage (Hipol \& Alma-in, 2018; Wern et al., 2016).

\subsection{Tapuy made from black rice had the highest antioxidant activity}

The DPPH radical scavenging activity of Tapuy made from different pigmented rice are shown in Figure 4. At day 0 of fermentation, black rice and red rice had DPPH radical scavenging activities of $25.88 \%$ and $22.27 \%$, respectively, which were significantly higher $(\mathrm{p}<0.01)$ compared to the $\mathrm{DPPH}$ radical scavenging activities of white rice and brown rice $(9.35 \%$ \& 9.99\%, respectively) (Figure 4). Walter et al. (2013) showed similar results where black and red rice had 8 to 14 times higher antioxidant activity compared to light brown rice. These differences in antioxidant activity were positively and significantly correlated $\left(\mathrm{R}^{2}=0.9099\right)$ with the total soluble phenolic compounds of the different pigmented rice (Goffman \& Bergman, 2004; Walter et al., 2013). The higher levels of phenolic compounds in black rice (i.e., anthocyanins, particularly cyanidin-3-glucoside \& peonidin-3-glucoside) and red rice (i.e., proanthocyanidins) may be responsible for their high antioxidant activities (Ghasemzadeh et al., 2018; Hou et al., 2013; Oki et al., 2002). As mentioned previously, Ballatinao black rice had the highest anthocyanin and total phenolic contents compared to red rice and non-pigmented or white rice, further suggesting the influence of anthocyanins and phenolic compounds on the antioxidant activity of black rice (Romero et al., 2012).

There was a significant increase $(\mathrm{p}<0.01)$ in the DPPH radical scavenging activity of the different Tapuy during the 7-day fermentation (Figure 4). The increase in antioxidant activity of the different Tapuy during fermentation may have been brought about by 2 possible mechanisms. First, the amount of available antioxidant compounds in the Tapuy may have increased through the action of starter culture microbial hydrolytic enzymes on the rice. Second, the alcohol produced during fermentation may have facilitated the extraction of antioxidant compounds in the rice. A study on the fermentation of Haria, an Indian fermented rice beverage, showed that the increase in antioxidant activity of this fermented rice beverage was related to the presence of higher amounts of oligosaccharide, phenolic compounds and 
flavonoids attributed to the action of hydrolytic enzymes from microorganisms during the course of fermentation (Ghosh et al., 2015). Apparently, this antioxidant activity increase is a common occurrence in fermentation, since it was also seen in several studies of fermentation of rice bran with Rhizopus oryzae, L. lactic, L. plantarum, Aspergillus awamori, and Aspergillus oryzae (Nisa et al., 2019; Oliveira et al., 2012; Shin et al., 2019). It is notable that these same microorganisms were also found in Tapuy fermented with Bubod (Sanchez, 1999). Another common microorganism in starter cultures, including Bubod, are yeasts. The production of alcohol by the action of yeast on rice starch may also contribute to the amount of phenolic compounds in rice wine by improving phenolic extraction during fermentation (Singkong, 2015).

The final DPPH radical scavenging activity of the different Tapuy were $45.44 \%$ to $70.63 \%$ (Figure 4 ). These values fall within the range of DPPH radical scavenging activity (50.0$88.5 \%$ ) of commercial Tapuy from Benguet, Philippines (Hipol \& Alma-in, 2018). Tapuy made from black rice exhibited the highest DPPH radical scavenging activity $(70.63 \%, \mathrm{p}<0.01)$ among the Tapuy made from different pigmented rice. This is consistent with the study by Koguchi et al. (2010), where they showed that rice wine made from purple/black rice had higher antioxidant activity compared to those made from ordinary brown rice and polished white rice. Similarly, Chay et al. (2020) also showed that Cambodian rice wine made from black sticky rice had higher antioxidant activity compared to those made from white sticky rice. There was a significant direct correlation

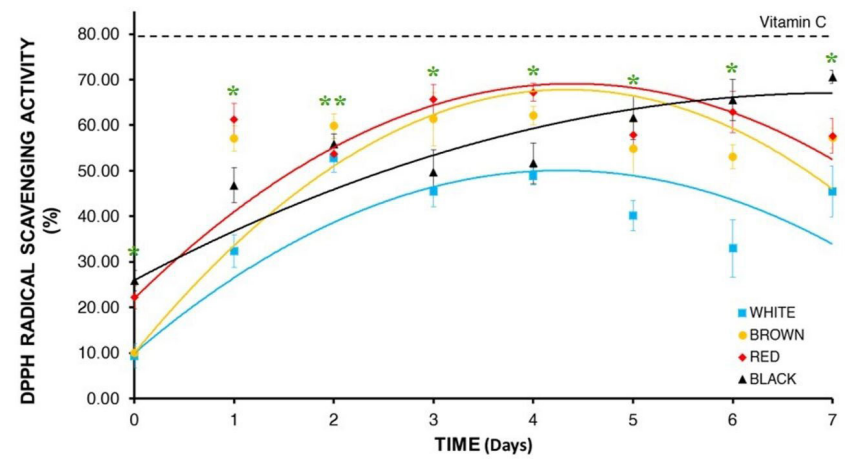

Figure 4. DPPH radical scavenging activity (\%) of Tapuy made from different pigmented rice during the 7 -day fermentation. Data points are the mean of 3 replicates. Error bars are the standard deviation for each data point. DPPH radical scavenging activity of the positive control (vitamin C) at $200 \mu \mathrm{g} / \mathrm{mL}$ is $79.97 \%$. Lines are the best-fit curve using a $2^{\text {nd }}$ order polynomial equation. There was an increase in the DPPH radical scavenging activities of Tapuy made from different pigmented rice. At day 0 , black rice and red rice already showed significantly higher $(\mathrm{p}<0.01)$ DPPH radical scavenging activities $(25.88 \%$ and $22.27 \%$, respectively) from brown rice and white rice $(9.99 \%$ and $9.35 \%$, respectively). At day 7, Tapuy made from black rice leveled-off at $70.63 \%$ DPPH radical scavenging activity; whereas Tapuy made from the other pigmented rice were declining. The final DPPH radical scavenging activities of the different rice wines after fermentation was $45.44 \%$ to $70.63 \%$, where Tapuy made from black rice showed the highest DPPH radical scavenging activity at $70.63 \% .{ }^{* *} \mathrm{p}$-value $<0.05 ;{ }^{*} \mathrm{p}$-value $<0.01$. between the DPPH radical scavenging activity and total phenolic content of the different Tapuy in this study $(\mathrm{r}=0.92, \mathrm{p}<0.01)$, suggesting that the high antioxidant activity of Tapuy made from Ballatinao black rice could be related to the high total phenolic and anthocyanin contents of this black rice variety. Previous studies of rice wines made from black rice showed that the high amounts of total phenolic compounds, including anthocyanins, found in black rice was related to the high antioxidant activity observed in the rice wines (Cai et al., 2019; Koguchi et al., 2010). The high anthocyanin content of Ballatinao black rice could also be responsible for the bioactivities in model organisms revealed from previous studies (Ona \& Medina, 2015; Quebral \& Medina, 2015; Velasco \& Medina, 2014). Interestingly, the final DPPH radical scavenging activity of Tapuy made from brown rice $(57.20 \%)$ was similar to the final DPPH radical scavenging activity of Tapuy made from red rice (57.66\%) (Figure 4). Even though brown rice had a significantly lower antioxidant activity than red rice at the start of fermentation, the antioxidant activity of brown rice could have been enhanced during fermentation by the release of phenolic compounds (e.g. ferulic acid \& p-coumaric acid) coming from the brown rice bran, which contains $70-90 \%$ of the total phenolic acid of the rice grain (Zhou et al., 2004).

\subsection{Tapuy made from different pigmented rice have distinct sensory profiles}

The sensory evaluations of Tapuy made from different pigmented rice are shown in Figure 5. Out of the six sensory

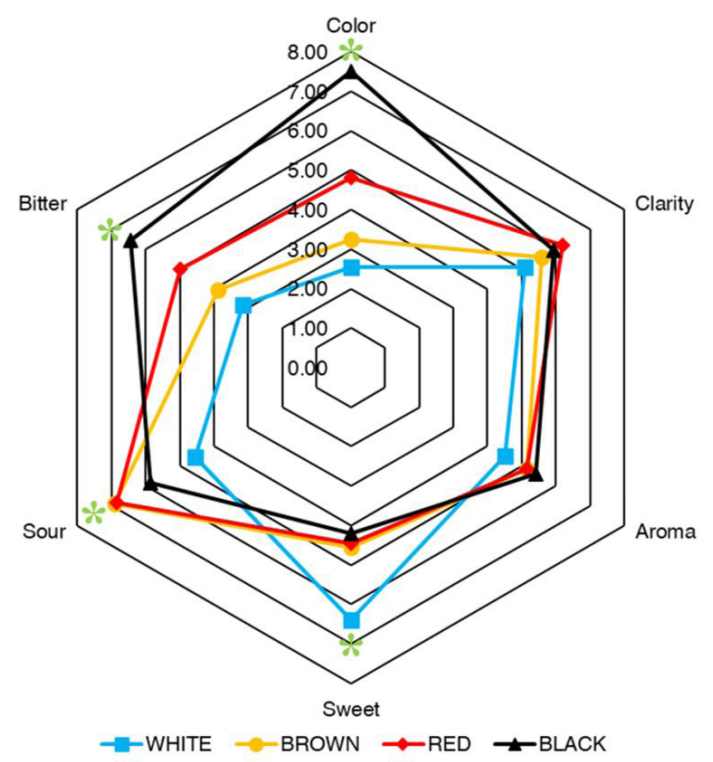

Figure 5. Sensory evaluation of Tapuy made from different pigmented rice after the 7-day fermentation. Data points represent the mean of each sensory attribute. All of the sensory attributes, except for aroma and clarity, showed significant difference $(\mathrm{p}<0.05)$ among the different rice wines. Tapuy made from black rice had the highest score on color (7.50) and bitterness (6.45) while Tapuy made from white rice had the highest score on sweetness (6.40). Means were compared by using Tukey's honest significant difference (HSD) test. ${ }^{*} \mathrm{p}$-value $<0.05$. 
attributes tested, i.e. color, sweetness, sourness, bitterness, clarity, and aroma, the last two did not show any significant difference ( $p>0.05$ ) among the different rice wines. Tapuy made from black rice had the highest score for color and bitterness $(7.50 \& 6.45$, respectively). The dark color and bitter taste of this rice wine may be attributed to the high anthocyanin and tannin contents, which is consistent with the observed high total phenolic content of the Tapuy made from this black rice variety (Table 1). Black rice had higher tannin and anthocyanin content in the bran layer compared to white rice (Bhattacharyya \& Roy, 2018; Jun et al., 2012). In red wine, these phenolic compounds were found to be the main contributing factor to the bitter/astringent taste (Ma et al., 2014).

Tapuy made from white rice had the highest score for sweetness (6.40) among the different rice wines. The glutinous Bongkitan white rice variety, which provides more substrate for molds in the Bubod starter culture, saccharify into more simple sugars that produce a sweeter Tapuy. Lai et al. (2019) showed that rice wine made from glutinous rice had higher water-soluble sugars and was sweeter than rice wine made from non-glutinous rice.

\section{Conclusions}

This was the first study to describe the basic properties of Tapuy fermentation using different pigmented rice (black, red, brown and white) available in Benguet, Philippines. Tapuy made from Ballatinao black rice had the highest alcohol content, total phenolic content and antioxidant activity. Thus, Tapuy made with Ballatinao black rice may qualify as a health-promoting functional food which could positively impact the food industry. This Tapuy can increase the consumer market of indigenous rice wines since younger generation of consumers are more aware that nutrition is important in disease prevention. An increased demand for a healthier rice wine will increase production and sales of this indigenous beverage resulting to a greater demand for manpower among farmers that cultivate heirloom rice. Increase cultivation of this heirloom rice variety (Ballatinao black rice) will help preserve this heirloom rice against competition from cultivated commercial white rice. This will then maintain the unique genes found in this heirloom rice which could be used for the genetic improvement of common rice varieties in the future. Finally, this will also help preserve the Cordillera indigenous culture and traditions surrounding this heirloom rice. It is recommended that studies determining and documenting the beneficial bioactivities of Tapuy made from Ballatinao black rice be pursued in order to fully establish and promote this alcoholic beverage as a functional food product.

\section{References}

Ablaza, M. J. C., Valerio, A. M., Mamucod, H. F., Bandonill, E. H., \& Romero, M. V. (2008). Utilization of pure molds and yeast in the preparation of tapuy (rice wine). Philippine Journal of Crop Science, 36(2), 34-41.

Baek, C., Choi, J., Choi, H. S., Jeong, S., Kim, J. H., Jeong, Y., \& Yeo, S. (2013). Quality characteristics of brown rice makgeolli produced under differing conditions. Korean Journal of Microbiology and Biotechnology, 41(2), 168-175. http://dx.doi.org/10.4014/kjmb.1210.10005.
Bandonill, E. H., Morales, A. V., Ablaza, M. J., Mamucod, H. F., \& Romero, M. V. (2009). Quality improvement and shelf-life enhancement of Philippine Tapuy (rice wine). Philippine Journal of Crop Science, 34(1), 12-18.

Banwa, T. P., Bawer, M. C., \& Doctor, J. G. P. (2020). Potential of Rice Culture Starter (RCS) for pre-fermenting Parboiled Rice Bran (PRB) through Solid-state Fermentation (SSF). Indian Journal of Science and Technology, 13(09), 1036-1045. http://dx.doi.org/10.17485/ ijst/2020/v013i09/148117.

Bhattacharyya, S., \& Roy, S. (2018). Qualitative and quantitative assessment of bioactive phytochemicals in gobindobhog and black Rice, cultivated in West Bengal, India. International Journal of Pharmaceutical Sciences and Research, 9(9), 3845-3851.

Cai, H., Zhang, Q., Shen, L., Luo, J., Zhu, R., Mao, J., Zhao, M., \& Cai, C. (2019). Phenolic profile and antioxidant activity of Chinese rice wine fermented with different rice materials and starters. Lebensmittel-Wissenschaft + Technologie, 111, 226-234. http://dx.doi. org/10.1016/j.lwt.2019.05.003.

Chay, C., Dizon, E. I., Hurtada, W. A., Elegado, F. B., Norng, C., \& Raymundo, L. C. (2020). Total phenolic content and antioxidant activity of rice wine from waxy pigmented and non-pigmented rice varieties produced by traditional and multi-parallel fermentation. Food Research, 4, 199-206.

Chay, C., Elegado, F. B., Dizon, E. I., Hurtada, W. A., Norng, C., \& Raymundo, L. C. (2017). Effects of rice variety and fermentation method on the physiochemical and sensory properties of rice wine. International Food Research Journal, 24(3), 1117-1123.

Coronel, L. M., Velasquez, A. O., \& Castillo, M. C. (1981). Some factors affecting the production of rice wine using an isolate of Aspergillus oryzae. Philippine Journal of Science, 110(1), 1-9.

Ghasemzadeh, A., Karbalaii, M. T., Jaafar, H. Z. E., \& Rahmat, A. (2018). Phytochemical constituents, antioxidant activity, and antiproliferative properties of black, red, and brown rice bran. Chemistry Central Journal, 12(1), 17. http://dx.doi.org/10.1186/s13065-018-0382-9. PMid:29455357.

Ghosh, K., Ray, M., Adak, A., Dey, P., Halder, S. K., Das, A., Jana, A., Parua Mondal, S., Das Mohapatra, P. K., Pati, B. R., \& Mondal, K. C. (2015). Microbial, saccharifying and antioxidant properties of an Indian rice based fermented beverage. Food Chemistry, 168, 196-202. http://dx.doi.org/10.1016/j.foodchem.2014.07.042. PMid:25172700.

Gobbetti, M., Di Cagno, R., \& De Angelis, M. (2010). Functional microorganisms for functional food quality. Critical Reviews in Food Science and Nutrition, 50(8), 716-727. http://dx.doi.org/10.1 080/10408398.2010.499770. PMid:20830633.

Goffman, F. D., \& Bergman, C. J. (2004). Rice kernel phenolic content and its relationship with antiradical efficiency. Journal of the Science of Food and Agriculture, 84(10), 1235-1240. http://dx.doi. org/10.1002/jsfa.1780.

Hipol, R. L. B., \& Alma-in, A. B. (2018). Antioxidant potentials of indigenously produced Benguet tapuy (rice wine). International Food Research Journal, 25(5), 1968-1976.

Hou, Z., Qin, P., Zhang, Y., Cui, S., \& Ren, G. (2013). Identification of anthocyanins isolated from black rice (Oryza sativa L.) and their degradation kinetics. Food Research International, 50(2), 691-697. http://dx.doi.org/10.1016/j.foodres.2011.07.037.

Huang, Y. P., \& Lai, H. M. (2016). Bioactive compounds and antioxidative activity of colored rice bran. Journal of Food and Drug Analysis, 24(3), 564-574. http://dx.doi.org/10.1016/j.jfda.2016.01.004. PMid:28911562.

Hur, S. J., Lee, S. Y., Kim, Y. C., Choi, I., \& Kim, G. B. (2014). Effect of fermentation on the antioxidant activity in plant-based foods. 
Food Chemistry, 160, 346-356. http://dx.doi.org/10.1016/j. foodchem.2014.03.112. PMid:24799248.

Jiang, L., Mu, Y., Wei, S., Mu, Y., \& Zhao, C. (2020a). Study on the dynamic changes and formation pathways of metabolites during the fermentation of black waxy rice wine. Food Science \& Nutrition, 8(5), 2288-2298. http://dx.doi.org/10.1002/fsn3.1507. PMid:32405386.

Jiang, L., Su, W., Mu, Y., \& Mu, Y. (2020b). Major metabolites and microbial community of fermented black glutinous rice wine with different starters. Frontiers in Microbiology, 11, 593. http://dx.doi. org/10.3389/fmicb.2020.00593. PMid:32362879.

Jin, J., Kim, S., Jin, Q., Eom, H., \& Han, N. S. (2008). Diversity analysis of lactic acid bacteria in Takju, Korean Rice Wine. Journal of Microbiology and Biotechnology, 18(10), 1678-1682. PMid:18955819.

Jun, H., Song, G., Yang, E., Youn, Y., \& Kim, Y. (2012). Antioxidant activities and phenolic compounds of pigmented rice bran extracts. Journal of Food Science, 77(7), C759. http://dx.doi.org/10.1111/j.17503841.2012.02763.x. PMid:22708681.

Kim, D.-R., Seo, B.-M., Noh, M.-H., \& Kim, Y.-W. (2012). Comparison of temperature effects on brewing of makgeolli using uncooked germinated black Rice. KSBB Journal, 27(4), 251-256. http://dx.doi. org/10.7841/ksbbj.2012.27.4.251.

Kim, E., Chang, Y. H., Ko, J. Y., \& Jeong, Y. (2013). Physicochemical and microbial properties of Korean traditional rice wine, Makgeolli, supplemented with banana during fermentation. Preventive Nutrition and Food Science, 18(3), 203-209. http://dx.doi.org/10.3746/ pnf.2013.18.3.203. PMid:24471133.

Koguchi, M., Saigusa, N., \& Teramoto, Y. (2010). Antioxidative activity of alcoholic beverages made from purple rice (Oryza sativa var. Indica cv. Shiun). Food Science and Technology Research, 16(2), 157-162. http://dx.doi.org/10.3136/fstr.16.157.

Kong, L., Wang, Y., \& Cao, Y. (2008). Determination of Myo-inositol and d-chiro-inositol in black rice bran by capillary electrophoresis with electrochemical detection. Journal of Food Composition and Analysis, 21(6), 501-504. http://dx.doi.org/10.1016/j.jfca.2008.04.005.

Kushwaha, U. K. S. (2016). Black rice: research, history and development. Switzerland: Springer. https://doi.org/10.1007/978-3-319-30153-2.

Lai, Q., Li, Y., Wu, Y., \& Ouyang, J. (2019). The quality of rice wine influenced by the crystal structure of rice starch. Journal of Food Science and Technology, 56(4), 1988-1996. http://dx.doi.org/10.1007/ s13197-019-03667-z. PMid:30996433.

Lee, I. H., Hung, Y. H., \& Chou, C. C. (2008). Solid-state fermentation with fungi to enhance the antioxidative activity, total phenolic and anthocyanin contents of black bean. International Journal of Food Microbiology, 121(2), 150-156. http://dx.doi.org/10.1016/j. ijfoodmicro.2007.09.008. PMid:18031859.

Lee, T., Hwang, D., \& Lee, C. (2009). Changes in yeast cell number, total acid and organic acid during production and distribution processes of makgeolli, traditional alcohol of Korea. The Korean Journal of Microbiology, 45(4), 391-396.

Ling, W. H., Cheng, Q. X., Ma, J., \& Wang, T. (2001). Red and black rice decrease atherosclerotic plaque formation and increase antioxidant status in rabbits. The Journal of Nutrition, 131(5), 1421-1426. http:// dx.doi.org/10.1093/jn/131.5.1421. PMid:11340093.

Ma, W., Guo, A., Zhang, Y., Wang, H., Liu, Y., \& Li, H. (2014). A review on astringency and bitterness perception of tannins in wine. Trends in Food Science \& Technology, 40(1), 6-19. http://dx.doi.org/10.1016/j. tifs.2014.08.001.

Moirangthem, K., Jenkins, D., Ramakrishna, P., Rajkumari, R., \& Cook, D. (2020). Indian black rice: a brewing raw material with novel functionality. Journal of the Institute of Brewing, 126(1), 35-45. http://dx.doi.org/10.1002/jib.584.

Nisa, K., Rosyida, V. T., Nurhayati, S., Indrianingsih, A. W., Darsih, C., \& Apriyana, W. (2019). Total phenolic contents and antioxidant activity of rice bran fermented with lactic acid bacteria. In IOP Conference Series: Earth and Environmental Science (Vol. 251). Tangerang, Indonesia. http://dx.doi.org/10.1088/1755-1315/251/1/012020.

Oki, T., Masuda, M., Kobayashi, M., Nishiba, Y., Furuta, S., Suda, I., \& Sato, T. (2002). Polymeric procyanidins as radical-scavenging components in red-hulled rice. Journal of Agricultural and Food Chemistry, 50(26), 7524-7529. http://dx.doi.org/10.1021/jf025841z. PMid:12475265.

Oliveira, M. S., Cipolatti, E. P., Furlong, E. B., \& Soares, L. S. (2012). Phenolic compounds and antioxidant activity in fermented rice (Oryza sativa) bran. Food Science and Technology, 32(3), 531-537. http://dx.doi.org/10.1590/S0101-20612012005000071.

Ona, K. A. L., \& Medina, P. M. B. (2015). Crude Anthocyanin Extract (CAE) from Ballatinao black rice reduces acute lead toxicity in Daphnia magna. Journal of Environment Pollution and Human Health, 3(1), 18-23. http://dx.doi.org/10.12691/jephh-3-1-4.

PhilRice. (2017). Heirloom rice preserved, made productive. Retrieved from https://www.philrice.gov.ph/heirloom-rice-preserved-madeproductive/

Prasad, B. J., Sharavanan, P. S., \& Sivaraj, R. (2019). Health benefits of black rice: a review. Grain \& Oil Science and Technology, 2(4), 109113. http://dx.doi.org/10.1016/j.gaost.2019.09.005.

Prieto, J. M. (2012). Procedure: preparation of DPPH Radical, and antioxidant scavenging assay (pp. 7-9). Retrieved from https://www. researchgate.net/post/Can_anyone_explain_the_DPPH_method_ for_antioxidant_activity_in_details

Priya, R. T. S., Raeboline, A., Eliazer, L., Ravichandran, K., \& Antony, U. (2019). Nutritional and functional properties of coloured rice varieties of South India: a review. Journal of Ethnic Foods, 3, 1-11.

Quebral, E. P., \& Medina, P. M. B. (2015). Crude Anthocyanin Extract (CAE) From Ballatinao Black Rice Hastens Regeneration In Dugesia hymanae. Journal of Pharmaceutical and Biomedical Sciences, 5(2), 147-153.

Rattanachitthawat, S., Suwannalert, P., Riengrojpitak, S., Chaiyasut, C., \& Pantuwatana, S. (2010). Phenolic content and antioxidant activities in red unpolished Thai rice prevents oxidative stress in rats. Journal of Medicinal Plants Research, 4(9), 796-801. http:// dx.doi.org/10.5897/JMPR10.067.

Romero, M., Ramos, N., Soco, O., \& Mamucod, H. (2012). Characterizing the nutraceutical content and enhancing the utilization of pigmented rice in the Philippines (pp. 19-22). Philippines: Philippine Rice R\&D Highlights.

Sakai, H., \& Caldo, G. A. (1985). Microbiological and chemical changes in tapuy fermentation. Journal of Fermentation Technology, 63(11), 11-16.

Sanchez, P. (1999). Microorganisms and technology fermented foods. Nihon Nyusankin Gakkaishi, 10(1), 19-28. http://dx.doi.org/10.4109/ jslab1997.10.19.

Sanchez, P. (2008). Rice wine (Tapuy). In P. Sanchez, Philippine fermented foods: priniciples and technology (pp. 97-121). Quezon City: University of the Philippines Press.

Selhub, E. M., Logan, A. C., \& Bested, A. C. (2014). Fermented foods, microbiota, and mental health: Ancient practice meets nutritional psychiatry. Journal of Physiological Anthropology, 33(1), 2. http:// dx.doi.org/10.1186/1880-6805-33-2. PMid:24422720. 
Shahidi, F., \& Ambigaipalan, P. (2015). Phenolics and polyphenolics in foods, beverages and spices: Antioxidant activity and health effects: a review. Journal of Functional Foods, 18, 820-897. http://dx.doi. org/10.1016/j.jff.2015.06.018.

Shin, H. Y., Kim, S. M., Lee, J. H., \& Lim, S. T. (2019). Solid-state fermentation of black rice bran with Aspergillus awamori and Aspergillus oryzae: Effects on phenolic acid composition and antioxidant activity of bran extracts. Food Chemistry, 272, 235-241. http://dx.doi.org/10.1016/j.foodchem.2018.07.174. PMid:30309538.

Singkong, W. (2015). The production of red wine from black jasmine rice. Journal of Food Research, 4(6), 69. http://dx.doi.org/10.5539/ jfr.v4n6p69.

Su, N. R., Sun, Z. P., \& Chi-Tang, H. (1998). High performance liquid chromatographic determination of anthocyanin pigments in some varieties of black rice. Journal of Food and Drug Analysis, 6(4), 6.

Sumbhate, S. V., Nayak, S., Goupale, D., Tiwari, A., \& Jadon, R. S. (2012). Colorimetric method for the estimation of ethanol in alcoholicdrinks. Journal of Analytical Techniques, 1(1), 1-6.

Takeshita, R., Saigusa, N., \& Teramoto, Y. (2015). Production and antioxidant activity of alcoholic beverages made from various colored rice and wild rice. African Journal of Biochemistry Research, 9(11), 130-136. http://dx.doi.org/10.5897/AJBR2015.0860.

Tanimura, W., Sanchez, P., \& Kozaki, M. (1977). The fermented food in the Philippines. I. Tapuy (rice wine). Journal of Agricultural Science, 22(1), 118-134.

Teramoto, Y., Koguchi, M., \& Wongwicharn, A. (2011). Production and antioxidative activity of alcoholic beverages made from Thai ou yeast and black rice (Oryza sativa var. Indica cv. Shiun). African Journal of Biotechnology, 10(52), 10706-10711. http://dx.doi.org/10.5897/ AJB10.1516.

Vattem, D. A., \& Shetty, K. (2003). Ellagic acid production and phenolic antioxidant activity in cranberry pomace (Vaccinium macrocarpon) mediated by Lentinus edodes using a solid-state system. Process Biochemistry, 39(3), 367-379. http://dx.doi.org/10.1016/S00329592(03)00089-X.
Velasco, A. J. D., \& Medina, P. M. B. (2014). Crude Anthocyanin Extract (CAE) from Ballatinao black rice does not alter longevity and increases stress susceptibility of Drosophila melanogaster. International Journal of Current Research in Biosciences and Plant Biology, 1(4), 35-42.

Walter, M., Marchesan, E., Massoni, P. F. S., da Silva, L. P., Sartori, G. M. S., \& Ferreira, R. B. (2013). Antioxidant properties of rice grains with light brown, red and black pericarp colors and the effect of processing. Food Research International, 50(2), 698-703. http:// dx.doi.org/10.1016/j.foodres.2011.09.002.

Wang, Q., Han, P., Zhang, M., Xia, M., Zhu, H., Ma, J., Hou, M., Tang, Z., \& Ling, W. (2007). Supplementation of black rice pigment fraction improves antioxidant and anti-inflammatory status in patients with coronary heart disease. Asia Pacific Journal of Clinical Nutrition, 16(Suppl. 1), 295-301. PMid:17392122.

Wern, K. H., Haron, H., \& Keng, C. B. (2016). Comparison of Total Phenolic Contents (TPC) and antioxidant activities of fresh fruit juices, commercial 100\% fruit juices and fruit drinks. Sains Malaysiana, 45(9), 1319-1327.

Xiang, H., Sun-Waterhouse, D., Waterhouse, G. I. N., Cui, C., \& Ruan, Z. (2019). Fermentation-enabled wellness foods: a fresh perspective. Food Science and Human Wellness, 8(3), 203-243. http://dx.doi. org/10.1016/j.fshw.2019.08.003.

Zhang, Z., Soccol, C., \& Pandey, A. (2012). Production of powerful antioxidant supplements via solid-state fermentation of wheat (Triticum aestivum Linn.) by Cordyceps militaris. Food Technology and Biotechnology, 50(1), 32-39.

Zhao, R., Wu, X., Seabourn, B. W., Bean, S. R., Guan, L., Shi, Y. C., Wilson, J. D., Madl, R., \& Wang, D. (2009). Comparison of waxy vs. nonwaxy wheats in fuel ethanol fermentation. Cereal Chemistry, 86(2), 145-156. http://dx.doi.org/10.1094/CCHEM-86-2-0145.

Zhou, Z., Robards, K., Helliwell, S., \& Blanchard, C. (2004). The distribution of phenolic acids in rice. Food Chemistry, 87(3), 401406. http://dx.doi.org/10.1016/j.foodchem.2003.12.015. 